\title{
Ecofeminismo e a participação das mulheres na gestão das águas
}

DOSSIER ÁGUA E MULHER

\section{Eldis Camargo}

Advogada. Mestre em Direito das Relações Sociais - Direito Ambiental [PUC/SP]; Doutora em Energia Elétrica [Escola Politécnica da USP]; Pós Doutora em Direitos Humanos [Universidade de Coimbra];

Professora e Servidora Pública. Brasília [DF] Brasil. <eldiscamargosantos@gmail.com>

\section{Resumo}

0 texto vem contextualizar o papel das mulheres na gestão dos usos dos recursos hídricos, mostrando o histórico do movimento feminista, notadamente voltado para o ecofeminismo, que determina o papel peculiar da mulher no trato com a natureza e quais são os caminhos traçados para integrar a sua participação em processos decisórios.

\section{Palavras-chave}

Gênero. Feminismo. Ecofeminismo. Princípios de direito. Gestão das águas.

\section{Ecofeminism and women's participation in water management}

\begin{abstract}
The text contextualizes the role of women in the management of the uses of water resources, showing the history of the feminist movement, especially focused on ecofeminism, which determines the peculiar role of women in dealing with nature and what are the paths drawn to integrate the participation in decisionmaking processes.
\end{abstract}

\section{Keywords}

Gender. Feminism. Ecofeminism. Principles of law. Water management. 


\section{Introdução}

A intenção nesse trabalho está focada em discorrer sobre as questões das mulheres relacionadas ao uso da água. Porém, antes, levantam-se os trâmites ocorridos nos processos históricos relacionados aos direitos das mulheres, com intuito de contextualizar a necessária participação das mulheres em processos decisórios, ligados à vida pública, até então somente adstrita aos homens. Da mesma forma, resumidamente, apresenta-se o estado da arte relativa às legislações concernentes à água e seus usos.

Assim, o primeiro item é dedicado a dois temas imbricados com as mulheres: gênero e feminismo; no primeiro caso, mostrando a construção social e cultural do termo e, no segundo, o que vem sendo discutido e entendido sobre a definição de feminismo.

Na construção dos direitos das mulheres, no segundo item, com base em momentos históricos da sociedade, são apresentados três momentos desse caminho, que os autores chamam de "ondas do movimento feminista".

0 terceiro item relata como tema ambiental, recebe a guarida constitucional e legal em nosso país, identificando a importância da participação das mulheres em pleitos para viabilizar a vida, o bem-estar e a dignidade. Nesse rastro, o quarto item, fala do ecofeminismo, um dos grupos que compõe a terceira onda do movimento feminismo.

O quinto item fala das águas e seus usos, vistos de forma diferenciada entre a Política do Meio Ambiente e a Política de Recursos Hídricos. 0 primeiro voltado para preservação e o segundo, direcionado para contabilizar e controlar os usos da água. Neste capítulo, são indicados documentos que visam possibilitar a entrada da mulher definitivamente na gestão das águas.

\section{Estamos falando do que?}

A construção social e cultural de identidade masculina e feminina é o que se entende por gênero, enquanto sexo caracteriza-se pelas características biológicas que definem um homem e uma mulher.

A primeira, por consignar uma característica cultural, recebe diversas dimensões correlacionadas a valores morais, muitas vezes ao revés de como a pessoa se enxerga e faz parte, feminino ou masculino. No caso das características biológicas, o ponto focal está inserido na genitália e cromossomos de como a pessoa veio ao mundo: macho, fêmea e intersexual.

Essas diferenças, até bem pouco tempo, não eram percebidas pelas pessoas. Sem adentrar neste tema, o certo é que a mulher sempre esteve aquém de conquistas referentes à cidadania e equidade diante de direitos, se comparadas aos dos homens.

Para esse trabalho, a diferenciação pouco irá importar, pois a análise caminha para construir a necessária participação da mulher (incluindo a identificação de gênero, se for o caso), em processos e procedimentos decisórios na gestão das águas.

A repressão sexual, causada notadamente pelo monoteísmo ${ }^{1}$, e o consequente patriarcado, acabaram gestando um entendimento de cunho cultural, o qual vem sendo contestado em diversos movimentos feministas: direito de participar de decisões políticas (voto, por exemplo), equidade em direitos trabalhistas (desigualdade salarial, por exemplo), liberdade sexual (aborto), dentre outras.

\footnotetext{
${ }^{1}$ As três religiões monoteístas dedicam nada menos que o papel de sub-humanas às mulheres. Em todas elas, são a "fonte" do pecado, da "tentação". Em todas elas, a personificação de deus é masculina. Em todas elas, o papel do sacerdócio é, invariavelmente, masculino: padres, rabinos e mulahs. Em todas elas, a maioria das restrições físicas de hábitos e costumes incide sobre as mulheres. Disponível em <https://jornalggn.com.br/blog/luisnassif/as-religioesmonoteistas-e-o-trato-dado-as-mulheres>.
} 
Contam lendas antigas, que sob o manto da harmonia do matriarcado, as questões sociais eram levadas a cabo com muito mais apreço ${ }^{2}$.

Imbuídas do sentimento de estarem ligadas aos ritmos da natureza, as mulheres compreendiam a interconexão entre esta e os seres humanos. A prevenção contra a destruição ambiental tinha seu ponto forte nesse vínculo. Assim, essa identificação tornou-se um projeto positivo, que as alçou ao nível de guardiãs da ecologia ${ }^{3}$.

Aqui não se busca identificar o conceito gerado pela dominação, tal qual o patriarcado apresenta, mas a proposta é reforçar as funções exercidas na condição de mulher, possuidoras, de forma inerente, do poder integrativo e cooperativo, dos princípios coletivos, da solidariedade e não destrutividade. Neste ponto, a correlação a que se quer chegar é a percepção do ganho social na participação das mulheres de forma igualitária em instâncias de decisão. Levando em conta, inclusive, seus conhecimentos técnicos e científicos e dando-lhe voz para apresentar o seu sentido na gestão das águas.

\subsection{Feminismo}

Cumpre estabelecer conceitualmente o termo "feminismo". De modo geral, o feminismo trata de um movimento social que rompe com a hierarquia do sexo masculino, pautando pela equidade política, econômica, jurídica e social, de ambos os sexos: mulheres e homens. Do latim "femina" mulher, os caminhos que se seguiram desse movimento, sem cair na tentação de ratificar modelos tradicionais (masculinizados), tiveram o cunho de superação de toda forma de discriminação, violência e exploração, pautando pela harmonização, participação na vida pública (até então restrita aos homens), e, notadamente, sem nenhuma vantagem de poder de um sexo ou de outro, pelo contrário, a proposta, de forma geral, é agregar saberes e condutas em prol de um presente e futuro digno para humanidade e para os planetas, em geral.

Historicamente, em 1759, Olympe de Gouges, em contraponto aos direitos dos homens, defendido no Iluminismo, lança o manifesto "Declaração dos Direitos da Mulher"4.

No Brasil, em 1827, surge a primeira legislação relativa à educação de mulheres, até então as mulheres só eram admitidas em escolas elementares. Nesse contexto, a brasileira Nísia Floresta lança, em tradução livre da feminista Mary Wolstonecraft, a obra "Direitos dos homens, injustiças para as mulheres".

De lá para cá, muitos acontecimentos se sucederam visando o "emponderamento" da mulher, com fortes repercussões de repressão, como é o caso das operárias mortas na fábrica têxtil Cotton, em Nova York, por conta de reivindicações voltadas à redução do horário de trabalho (de dezesseis para dez), licença maternidade, melhores salários, dentre outros interesses.

Somente em 1932, o novo Código Eleitoral, (Decreto no 21.976), garantiu o direito ao voto às mulheres no Brasil. Do ponto de vista internacional, coube à Organização Internacional do Trabalho (OIT), em 1951, aprovar a Convenção de Igualdade de remuneração entre o trabalho masculino e feminino para a mesma função. Na década de sessenta, época de grandes contestações sociais, surge um novo feminismo, paralelo, as grandes manifestações em prol de direitos civis e políticos (direitos fundamentais).

\footnotetext{
2 "A queda do direito maternal foi a grande derrota histórica do sexo feminino. 0 homem toma o governo da casa, também; a mulher foi degradada, dominada, tornando-se escrava do prazer do homem e simples instrumento de reprodução. Friedrich Engels, Origem da família da propriedade privada do Estado, p. 68.

3 Janet Biehl. A mulher e a natureza: uma mística recorrente, Le monde diplomatique, maio de 2011. Disponível em <http://diplomatique.org.br/a-mulher-e-a-natureza-uma-mistica-recorrente/>.

${ }^{4}$ Biblioteca Virtual de Direitos Humanos (SP). Disponível em <http://www.direitoshumanos.usp.br>.
} 
A partir dessa década, o movimento feminista se consolidou com várias pautas, inclusive sendo inferido o Ano Internacional da Mulher, em 1975. No Brasil, seguiram-se a criação do Conselho da Mulher, delegacias especializadas, instituição de cotas em âmbito parlamentar.

O certo é que todo arsenal de lutas focando direitos da mulher, acabou por mostrar que as mulheres são capazes de sustentar sozinhas suas famílias e que não havia mais como tratá-las apenas como donas de casa ou objeto de prazer.

\section{As três ondas do movimento feminista}

A história do movimento feminista passa por três momentos ao longo do tempo, chamadas ondas do feminismo 5 . Em um primeiro momento, as solicitações estavam ligadas à promoção da igualdade de direitos e liberdade (contratuais, propriedade, sufrágio ${ }^{6}$ por parte das mulheres dentre outras reivindicações) ocorridas no século XIX e início do século XX. Caracterizou-se esse período em levantar questões como a submissão da mulher ao homem e sua exclusão social, quando a mulher estava vinculada somente à esfera privada, excluída da vida pública. Nessa perspectiva, mulheres defensoras, dos primeiros movimentos feministas, fundamentavam direitos ao voto7, à educação feminina, à liberdade de se afastar de casamentos, até então arranjados pela família.

A segunda onda se estendeu no período que vai a partir da década de 1961, até o fim dos anos 80. Em continuidade com a primeira onda, reforçaram-se questões ligadas à igualdade e ao fim da discriminação, notadamente à sujeição masculina.

A principal característica da terceira onda, no início da década de 1990, estava pautada em um contraponto das afirmações da segunda onda referente às definições pautadas por mulheres brancas e da "classe média alta". Nesta seara, as propostas defendidas, de certa forma, as conquistas sociais e políticas estavam sendo consagradas por diversos documentos legais. Agora o movimento se concentrou em uma interpretação fixada em gênero e sexualidade. Defendendo, nesta perspectiva, que há importantes diferenças inerentes entre homens e mulheres. Entraram na pauta temas das mulheres negras, homossexuais, pobres, estendendo a discussão não somente à mulher, mas para a questão de gênero. Nesse contexto, entra na discussão do tema ambiental.

De forma paralela, pode-se contabilizar que o movimento feminista caminhou na consolidação

\footnotetext{
${ }^{5}$ Por que se fala em ondas dos feminismos? Se estes não se referem apenas a direitos iguais para mulheres e homens, qual seria o seu alcance? Sobre o que versa o seu conceito como um movimento plural e não unitário? Segundo Sally Scholz no livro "Feminism: A beginner's guide", de 2010, "feminismo é um projeto crítico" que se volta para aspectos que parecem opressivos às mulheres, oferecendo sugestões alternativas em termos de análises, práticas e discursos. A preferência atual pelo uso do termo no plural tem em vista a desconstrução dos papéis sociais e binários entre sexos e gêneros que alimentam o patriarcado. Nesse sentido, ao se tentar entender as bases sobre as quais se assentam os feminismos, deve-se levar em consideração a vida das mulheres como ponto de partida para teorias e práticas, ressaltando os caminhos dos quais as mulheres foram excluídas e problematizando as supostas características que reproduzem o sentido de serem mulheres. Todas essas questões nos remetem claramente às chamadas ondas feministas, ou seja, as gerações dos projetos feministas, muitas vezes controversas em nível teórico e prático. 0 termo ondas (the waves terminology) é elucidativo enquanto um projeto que ainda não se completou, em dois sentidos. 0 primeiro corresponde a um parâmetro cronológico ou de gerações. 0 segundo liga-se às sucessivas construções teórico-temáticas. Ambas as interpretações pressupõem que, tal como ondas no oceano, com marés (ebbs) e fluxos (flows), com marés altas e baixas, o reconhecimento das ondas pretende mapear a "intensidade variável da atividade feminista em diferentes períodos de tempo", acrescenta Scholz. P Feminismo e suas ondas. Magda Guadalupe dos Santos. Grupo Culti, em 5 de setembro de 2017.
}

6 Em 1922, nasce a Federação Brasileira pelo Progresso Feminino, com o objetivo de lutar pelo sufrágio feminino e o direito ao trabalho sem a autorização do marido. As sufragistas brasileiras capitaneadas pela bióloga Bertha Lutz e pela Engenheira Carmem Portinho criaram organizações, polemizaram na imprensa, escreveram discurso e criaram o Partido Republicano Feminino, em 1910.

7 "Seu grupo de tolas repugnantes", escreve o remetente. "Se vocês não têm lares, nem maridos, nem filhos e nem relações, por que não saem do caminho se afogando?" Uma das mensagens recebidas pelas sufragistas (1909) em cartões postais enviados. Disponível em: <https://www.buzzfeed.com/hazelshearing/sufragistas-xingadas-comohoje-mulheres-sao>. 
das máximas da revolução francesa: liberdade, igualdade e fraternidade. 0 processo foi formatado, de certa forma, para os direitos e interesses metaindividuais, como é o caso do tema ambiental. Hoje formulado a partir da ideia do "res ominus" - coisa de todos e todas, amplia-se o leque de reinvindicações e participação em processos decisórios e reivindicatórios, sempre apostando na diversidade.

No caso das mulheres, o lema estendeu-se para sonoridade, ou seja, a formação de aliança de mulheres, refutando estereótipos preconceituosos, criados por sociedade machista e patriarcal.

\section{Meio Ambiente}

A expressão meio ambiente, etimologicamente designa-se, de um lado o termo "ambiente"= amb+ire: ir em volta de; e de outro o termo "meio", significando algo central. Nessa perspectiva, meio ambiente seria tudo que está em volta de algo. Do ponto de vista antropocêntrico, seria tudo que está em volta do ser humano. Diferentemente, o biocentrismo, prega a importância de todas as formas de vida de forma igualitária. 0 ápice desse pensamento se reflete no entendimento que a natureza, no nosso caso, os cursos de água são titulares de direitos.

Na legislação brasileira, levando em conta a conceituação do inciso I do art. $3^{\circ}$ da Lei no 6.938 , de 1981, somado aos termos fixados no art. 225 da Constituição Federal, o meio ambiente é um conjunto de condições, leis e influências e interações de ordem física, química e biológica, que permite, abriga e rege a vida em todas as suas formas. A Constituição Federal acrescenta para essa definição o teor social e ecológico para as presentes e futuras gerações.

Vários temas ambientais se interlaçam com os interesses das mulheres. Já nos primórdios do movimento ambiental, a bióloga e ecologista norte-americana, Rachel Carson, levantou a tese polêmica dos malefícios das substâncias químicas tóxicas para saúde e o meio ambiente.

É cediço por todos que militam na área ambiental da denúncia sobre os males do DDT (diclorodifeniltricloroetano), até então, apontado como um efeito revolucionário no combate insetos, produção agrícola e febre amarela, dando a Hermann Muller o Nobel de Medicina em 1948. Logo, porém, seus efeitos foram sendo levantados em notícias e episódios de contaminação da água e morte de animais. Consta no trabalho Primavera Silenciosa, de Rachel Carson, que a presença de agrotóxico foi encontrada em quase todos os tipos de alimentos, inclusive no leite materno.

Hoje já estão consagrados pelos cientistas os males causados pelos pesticidas, sem a devida cautela de uso, contaminando correntes de água (rios e lagos) e fragilizando a qualidade dos recursos hídricos e o bem-estar das mulheres. Mas, os danos ainda continuam surtindo seus efeitos:

As mães que vivem em Lucas do Rio Verde, norte de Mato Grosso, estão assustadas com uma pesquisa que revelou a presença de resíduos de agrotóxicos no leite materno. "Uma disenteria [no bebê] e eu não sabia do que era, mas passou. Não sei se era por isso", conta a dona de casa Lucilene Araújo.

O medo veio com o resultado de uma pesquisa feita pela Universidade Federal de Mato Grosso em Lucas do Rio Verde (UFMT) a 350 quilômetros de Cuiabá. Foi analisado o leite de 62 voluntárias. Em todas as amostras, foi encontrado, pelo menos, um tipo de agrotóxico, como o DDT, proibido desde 1998. Em 76\% das amostras, foi detectado o Endossulfam, que deixara de ser usado a partir de julho de 2013. "Se o nível for bastante elevado, uma das causas dos vários tipos de câncer e de vários distúrbios endócrinos da mulher é causado por este tipo de agrotóxico", explica Wanderlei Pignati, pesquisador da $U F M T^{8}$.

Em outros temas, não é diferente, como é a questão das mudanças climáticas, desmatamentos, resíduos (lixões). No processo histórico da nossa civilização, homens e mulheres são atingidos de

8 Globo. Bom dia Brasil, edição de 31 de março de 2011. Disponível em <http://g1.globo.com/bom-dia-brasil/noticia/ 2011/03/presenca-de-agrotoxicos-em-leite-materno-assusta-mulheres-de-mt.html>. 
formas diferentes pelos problemas socioeconômicos e também ambientais. No contexto da nossa sociedade atual, as mulheres ainda possuem menores oportunidades de acessar os recursos materiais e sociais, assim como de tomar decisões em assuntos que afetam sua vida e o funcionamento da sociedade 9 .

São incontáveis as relações do meio ambiente com a mulher, ora sofrendo as consequências de imposições perversas quanto ao uso de materiais agressivos ao seu bem-estar e de sua prole, escolhidos "pelos homens", na maioria das vezes, para perpetuar um modelo que foge à lógica do cuidado. Quantas propagandas nos rodeiam com fórmulas fabulosas para emagrecer, cuidados com a pele, alimentos cheios de agrotóxicos oferecidos para nossas crianças.

Aos poucos, contudo, o cenário está sendo alterado com a adesão cada vez maior de mulheres envolvidas em temas com fito de salientar seus direitos e, na seara ambiental, perpetuar a vida no planeta. Têm-se difundido cada vez mais, círculos de mulheres que evocam sua relação da mulher com a natureza: são mulheres guardiãs da Terra, das Águas e dos Biomas, com o firme propósito de resgatar a relação do feminino com a natureza e com as tradições culturais.

Como salienta Leonardo Boff $10,[\ldots]$

[...] o poder em forma de dominação representa uma patologia, sendo produto do patriarcado a ciência e desenvolvimento que praticamos. O princípio feminino opera em outra lógica, tendo como mote maior, a vida e a não agressão, o inclusivo e não a exclusão, a cooperação e não a competitividade, ainda que culturalmente se operem em muitas mulheres posturas machistas evidenciando a continuidade de caminhos apartados da solidariedade.

Grande parte das famílias, hoje, são comandadas por mulheres!11 São elas que passam valores ecológicos e sociais aos filhos, são elas que cuidam dos anciões, lutando por sua saúde junto a processos de medicina, totalmente apartados de generosidade. Trabalham em locais insalubres, físico e moralmente, sem nenhum alento sequer. Destaque: ocupam espaços públicos e dão conta de tudo e de todos e todas. Ou seja, os valores e percepções femininos, quer técnicos, científicos, políticos, dentre outros, são pouco observados e acatados pelos pares masculinos.

No site do Movimento Empresarial pelo Desenvolvimento Econômico da Mulher, encontra-se a explicação dessas condutas:

Segundo a Fundação Tide Setubal, manterrupting, bropriating, gaslightinge, mansplaining são alguns dos termos criados para sinalizar o machismo nas relações e qualificar o comportamento masculino em relação a uma mulher em diferentes situações ${ }^{12}$.

\section{Ecofeminismo}

O termo surgiu em 1974, utilizado por Françoise d'Eaubonne, a partir da obra "Le feminism ou la Mort" (feminismo ou a morte). No contexto dos endereçamentos da terceira onda, mantiveramse os pleitos iniciais das ondas anteriores, mas acrescentou-se a ligação das mulheres com a

\footnotetext{
${ }^{9}$ Débora Mulhoz. Mulheres e Mudanças Climáticas. Disponível em <https://deborahmunhoz.wordpress.com/ publicacoes/artigos/mulheres-e-mudancas-climaticas/>.

10 Disponível em <http://grupelho.com/textos/principiofeminino.htm>.

110 número de lares brasileiros que tem como referência a mulher cresceu de 23\% para 40\% no período de 1995 a 2015. Valor Econômico em 6, de março de 2017.

12 Manterrupting: quando um homem interrompe constantemente uma mulher, de maneira desnecessária, não permitindo que ela conclua sua frase; mansplaining: quando um homem dedica seu tempo para explicar algo óbvio a uma mulher de forma didática, como se ela não fosse capaz de entender; bropriating: quando o homem se apropria da mesma ideia já expressa pela mulher, levando os créditos por ela; e gaslighting: abuso psicológico que leva a mulher a achar que enlouqueceu ou está equivocada sobre um assunto, sendo originalmente certa, fazendo que a mulher duvide do seu senso de percepção, raciocínio, memórias e sanidade. Disponível em <http://movimentomulher360.com.br>.
} 
ecologia. 0 princípio dessa vertente voltou-se para levantar o tema da dominação abarcada pelo sistema patriarcal, em que, tanto a mulher, como a natureza, é considerada, nessa dimensão, elementos mais fracos, hierarquicamente, sendo manejados para atender propósitos do dominador. Ou seja, mulheres e natureza compartilham o sistema de opressão, além do que as mulheres são as que mais sofrem com os danos ambientais (inclusive, sem ter participado de decisões a respeito de projetos e planos que tragam lesões ambientais). Na vertente ecofeminista, todos os seres do planeta têm importância aos moldes apregoados pela teoria do biocentrismo desenhada por uma composição ética no cuidado do planeta.

\section{Como apontam Raewyn Connel e Rebecca Pearse13, [...]}

[...] as ciências sociais quantitativas produziram evidências de que as emissões de gases de efeito estufa por habitante são menores em nações onde as mulheres têm um status político mais alto" e "nações com maiores proporções de mulheres no Parlamento têm mais chances de ratificar tratados ambientais do que outras nações.

Na seara do meio ambiente cultural, as expressões que garantem guarida a diversos ritos religiosos à água são referenciadas, como símbolo de pureza, concedendo às mulheres papéis de destaque, como no cristianismo a imagem de Nossa Senhora dos Navegantes; situações históricas, como o aparecimento no rio Paraíba de Nossa Senhora Aparecida; deusas místicas e protetoras da água, como, Oxum (Rainha das Cachoeiras), Naiades (ninfas dos rios, fontes e cascatas). Importante citar a grande a deidade máxima na região andina, Pacha Mama, a grande mãe protetora da Terra, hoje reconhecida em países latino-americanos como um novo sujeito de direito.

Manifestações pontuais que correm o mundo mostram engajamentos relacionados à preservação da água. Recentemente, a líder colombiana Francia Márquez ganhou o prêmio "The Goldman Environmental Prize 2018", por organizar um grupo de mulheres para evitar a extração minerária ilegal de ouro, que gerava um impacto negativo em fontes hídrica, com lançamento de mercúrio e produtos químicos contaminando o único recurso de água pura (rio Ovejas) ${ }^{14}$.

Vários movimentos têm se espalhado pelo mundo e pelo Brasil, onde mulheres atuam nas áreas de saneamento, visando o bem-estar do meio ambiente urbano, e no âmbito do meio ambiente do trabalho, onde aos poucos são levantadas as questões relativas à violência moral e sexual. Não se pode olvidar das situações de mulheres indígenas, quilombolas, caiçaras, quebradeiras de coco, que além de condições bem frágeis no cômputo dos direitos e interesses das mulheres, veem suas terras, suas culturas e sanidade hídricas ameaçadas por projetos e planos que não as protegem, nem a seus filhos ou sua comunidade ${ }^{15}$. Desta feita, caberá a cada uma acolher, em suas práticas, caminhos que estejam perfilhados com saberes sociais e ecológicos, e, ainda conhecer, estudar e garantir o bem-estar das presentes e futuras gerações, participando de pleitos que possam beneficiar e adequar processos decisórios que garantam, também, o direito de todas as mulheres.

\section{A gestão das Águas}

Consideram-se recursos ambientais, dentre outros, as águas superficiais e subterrâneas (inciso V

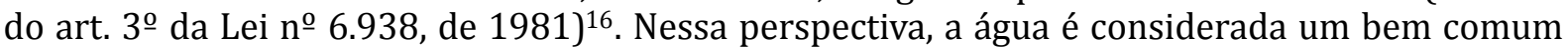

13 Disponível em <http://www.modefica.com.br/ecofeminismo-novas-perspectivas-e-desafios/\#.WqksbOjwaUk>.

14 Disponível em <http://caracol.com.co/radio/2018/04/23/ecologia/1524520305_916811.html>.

15 Em 30 de janeiro de 2017, ocorreu em São Paulo o Seminário Mulheres Atingidas por Barragens na Luta e a Luta por Direitos. Com a presença de 100 atingidos e atingidas de 18 estados do país, o encontro apresentou a experiência do projeto realizado pelo $\mathrm{MAB}$, em parceria com a Christian Aid e apoio da União Europeia, de empoderamento das mulheres atingidas na região do Tapajós. Foram mais de 300 mulheres que participaram de oficinas, seminários e discussões durante dois anos, entre fevereiro de 2015 e janeiro deste ano, com o enfoque na igualdade de gênero, combate à violência, organização das mulheres e acesso a políticas públicas. A maioria dessas mulheres são ameaçadas pelas sete barragens que estão previstas para serem construídas na bacia do rio Tapajós. Disponível em <http://www.mabnacional.org.br/noticia/semin-rio-discute-luta-das-mulheres-atingidas-por-direitos>.

16 Importante destacar que o termo socioambiental representa uma redundância, pois o termo já consagra o social. Seria mais acertado, ou somente colocar o termo ambiental, ou sócio/ecológico. 
do povo de titularidade difusa, fator que determina uma participação democrática em processos decisórios no âmbito dos poderes executivos da União, Estados, Distrito Federal e Municípios sob a luz da Constituição Federal e da Política Nacional do Meio Ambiente.

Porém, a salvaguarda para preservação e conservação da água recebe outro componente legal aos moldes apregoados pela Política Nacional de Recursos Hídricos, na qual se vê incumbida, por meio dos órgãos e entidades do Sistema de Gerenciamento de Recursos Hídricos, de gerenciar os usos da água. Desta feita, as competências se mesclam "água/recursos hídricos" em um intricando arsenal jurídico tornando complexa a ingerência.

Com fito de mostrar o arranjo atual na gestão de recursos hídricos, segue um pequeno resumo da situação pautada na Lei no 9.433, de 1997:

Fundamentos: Em seu artigo 1ํㅡ, nomeia a água como um bem de domínio público e dita que a mesma é um recurso natural limitado e dotado de valor econômico, cuja gestão deve proporcionar seu uso múltiplo. Prioriza, em situações de escassez, o consumo humano e a dessedentação de animais. Aponta que a gestão dos recursos hídricos deve ser descentralizada e contar com a participação do Poder Público, dos usuários e das comunidades. Nomeia a bacia hidrográfica como a unidade territorial para implementação da PNRH.

Objetivos: Esta Lei tem como meta a disponibilidade de água para as atuais e futuras gerações em padrões de qualidade para o seu uso, sua utilização racional e integrada (inclusive o transporte aquaviário), a prevenção e defesa contra eventos hidrológicos de origem natural ou por uso inadequado dos recursos naturais.

Diretrizes: Na implementação da PNRH, os agentes responsáveis, em especial os tomadores de decisão, devem primar pela gestão das águas, contabilizando sua qualidade e quantidade diante das diversidades físicas, bióticas, demográficas, econômicas, sociais e culturais das diversas regiões do país. Deve-se compatibilizar a integração da gestão de recursos hídricos com a ambiental, articular o planejamento do seu uso e descarte com os demais projetos adotados para os diversos usuários da água e com os planos traçados: regionais, estaduais e nacionais e o uso do solo. A gestão das bacias hidrográficas deve ser operacionalizada de forma articulada com a administração dos sistemas estuarinos e zonas costeiras.

Instrumentos da Política Nacional de Recursos Hídricos: Para implementar a PNRH, o legislador pátrio aponta os seguintes mecanismos: os planos de recursos hídricos; as outorgas de direito de uso de recursos hídricos; o enquadramento dos corpos de água em classes, segundo seus usos preponderantes; a cobrança do uso de recursos hídricos e a informação sobre os recursos hídricos. 0 modelo conta, também, com um sistema de fiscalização administrativa.

Sistema Nacional de Gerenciamento de Recursos Hídricos: Cumprindo o propósito da gestão participativa das águas, fixada na Política de Recursos Hídricos, a Lei das Águas estabelece um interessante Sistema Nacional de Gerenciamento que conta com os seguintes componentes:

1. Conselho Nacional de Recursos Hídricos - CNRH: composto de representantes dos Ministérios, das Secretarias da Presidência da República, dos Conselhos Estaduais, dos usuários e das organizações civis17e com as competências, dentre outras: promover a articulação do planejamento, analisar alterações na legislação e diretrizes complementares para gestão;

2. Comitês de Bacia Hidrográfica - CBH: integram os representantes da União, Estados, do Distrito Federal, dos Municípios, dos usuários e entidades civis e têm competências próprias, como, por exemplo, promover os debates das questões relacionadas aos recursos hídricos da bacia, aprovar o Plano de Recursos Hídricos e estabelecer mecanismos de cobrança;

170 parágrafo único do art. 34 determina que o número de representantes do Poder Executivo Federal não poderá exceder à metade mais um do total dos membros do Conselho Nacional de Recursos Hídricos. 
3. A Agência de Água tem como função manter balanço sobre a disponibilidade hídrica de recursos hídricos em sua área de atuação, acompanhar a administração financeira dos recursos arrecadados com a cobrança, promover estudos para gestão, etc.;

4. Agência Nacional de Águas: é competente para implementar, em sua esfera de atribuição, a PNRH e integrar o SINGREH;

5. Ministério do Meio Ambiente: por meio da Secretaria de Recursos Hídricos, cuida da coordenação política, atuando como Secretaria Executiva do CNRH, cuja finalidade é prestar apoio administrativo, técnico e financeiro ao Conselho Nacional de Recursos Hídricos, bem como coordenar a elaboração do Plano Nacional de Recursos Hídricos, dentre outras atribuições.

Também integram o sistema de gerenciamento, os órgãos dos poderes públicos estaduais, do DF e dos Municípios, cujas competências se relacionem com a gestão de recursos hídricos.

O Manual de Capacitação organizado por Lara Blanco 18 ensina que em relação aos direitos das mulheres à água, essencialmente existem três âmbitos de aplicação: água potável para uso doméstico; água para irrigação; e manutenção das águas subterrâneas. No Brasil, particularmente, há incidência de mais fatores que incorrem em regras para captação e lançamento de resíduos em cursos de água; empreendimentos que perpassam tanto pela gestão hídrica, contabilizando a quantidade de uso, como a dimensão de impactos ecológicos e sociais na seara ambiental.

Além do que outros setores estão imbricados nesse complexo modelo: como a área de saneamento, do setor elétrico, da saúde, da irrigação, recreação, mineração, dentre outros. Por outra banda, seguimentos sociais se debatem em torno do uso da água, e quase sempre as minorias sociais (como é o caso da mulher, comunidades indígenas, quilombolas, caiçaras) são prejudicadas.

Em interessante trabalho a respeito de mulheres rurais da América Latina e do Caribe, situou-se o debate sobre a água, registrando as mazelas em relação à participação das mulheres ${ }^{19}$ :

Também foi destacado pelas mulheres que os instrumentos de controle social ainda são incipientes, e não garantem sua participação nos espaços decisórios, capazes de alterar a conjuntura política. Portanto, as ações governamentais continuam sendo construídas sem o envolvimento efetivo das mulheres e populações rurais.

$[\ldots]$

Para que a participação não seja considerada extensão das tarefas domésticas, ou, assuma função instrumental, é basilar que as mulheres façam parte das instâncias decisórias. Quando os programas de desenvolvimento não se refiram às mulheres explicitamente, eles contribuem para reforçar a invisibilização das mulheres rurais como produtoras e como sujeitos políticos.

Desde a mais instruída das mulheres até a mais carente em termos econômicos, todas, de certo modo, mesmo sem a percepção pontual, em algum momento de suas vidas vão prescindir do maior esclarecimento do papel da mulher na sociedade e a importância da comprometida gestão das águas. Mas o certo é que são os homens que ocupam os espaços participativos para gestão das águas e tomam as decisões finais.

\footnotetext{
182002 Los Derechos de las Mujeres a la Tierra, Agua y Otros Recursos Naturales. Manual de capacitación para personal técnico de proyectos de desarrollo rural, instituciones públicas, y de la cooperación internacional. Coordinación General del Proyecto Sembrando Cambios en Centroamérica: Lara Blanco Felicia Ramírez. Serie Metodológica Sembrando Cambios Fundación Arias para la Paz y el Progreso Humano

${ }^{19}$ Revista Anthropológicas, ano 16, volume 23(1): 2012 Mulheres e água: a experiência da rede de mulheres rurais da América Latina e do Caribe Rosineide de L. Meira Cordeiro, Sandra Maria Batista Silveira, Paola Morales, e Vanete Almeida. Disponível em <http://www.revista.ufpe.br>.
} 
Um exemplo que se pode citar está na composição do Conselho Nacional de Recursos Hídricos (CNRH), dentre os titulares, 51 representantes são homens e 16 são mulheres.

Com esse tom, iniciaram-se pleitos para a representação feminina e inclusiva da mulher na gestão das águas. Sem desmerecer as realizações legais, afeitas a Tratados Internacionais, formação de Conselhos, Comitês e Delegacias de Mulheres, pontuam-se aqui arranjos voltados para a seara hídrica, como é o caso do princípio três da Declaração de Dublin sobre Água e Desenvolvimento Sustentável, ocorrido em Dublin, na Irlanda em 31 de janeiro de 1992, no seguinte sentido:

\begin{abstract}
"Princípio $n^{\circ} 3-$ As mulheres formam papel principal na provisão, gerenciamento $e$ proteção da água. Este papel de pivô, que as mulheres desempenham como provedoras e usuárias da água e guardiãs do ambiente diário, não tem sido refletido na estrutura institucional para o desenvolvimento e gerenciamento dos recursos hídricos. A aceitação e implementação deste princípio exigem políticas positivas para atender às necessidades específicas das mulheres equipando e capacitando-as para participar em todos os níveis dos programas de recursos hídricos, incluindo tomada de decisões e implementação de modo definido por elas próprias".
\end{abstract}

Esse princípio e os demais tornaram-se recomendações para os líderes mundiais que iriam participar da Conferência das Nações Unidas sobre Meio Ambiente e Desenvolvimento ocorrida no Rio de Janeiro em 1992 (Rio 92). Os princípios acatados em Dublin foram ratificados quando do estabelecimento da Política Nacional de Recursos Hídricos, em 1997, no Brasil, com exceção do Princípio três.

A partir daí, os movimentos feministas (ecofeministas) têm pautado a inclusão desse fundamento em suas políticas pátrias, resultando, no Brasil, a apresentação de proposta feita pela Agência Nacional de Águas, por meio do Projeto Legado 20 , preconizando o seguinte ajuste: o artigo $1^{\mathrm{o}}$ da Lei no 9.433, de 8 de janeiro de 1997, passa a vigorar com a seguinte redação:

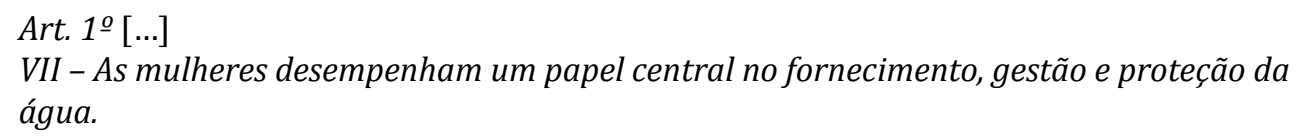

VII - As mulheres desempenham um papel central no fornecimento, gestão e proteção da água.

A ideia é que se pense, por exemplo, em maior equidade de gênero, e, notadamente à inclusão de mulheres em instâncias decisórias, como nos Comitês de Bacia Hidrográfica e Conselhos de Recursos Hídricos. Para que sejam educadas e instadas à participação, podendo inserir seus pleitos.

A título de contribuição vale a pena citar mais dois dispositivos que induzem a participação das mulheres em pleitos ambientais. Dentre os princípios formulados durante a Rio 92, o de no 20 estabeleceu que "As mulheres têm um papel vital no gerenciamento do meio ambiente e no desenvolvimento. Sua participação plena é, portanto, essencial para se alcançar o desenvolvimento sustentável.

No que concerne aos objetivos do desenvolvimento sustentável, adotado em 2015 na Cúpula das Nações Unidas, o objetivo 5 dispôs "alcançar a igualdade de gênero e empoderar todas as mulheres e meninas".

\title{
7. Conclusões
}

É certo que frente à égide do patriarcado que domina as relações políticas, civis, econômicas e sociais há mais de cinco mil anos, as reivindicações das mulheres, já ocorrendo desde o século passado, ainda estão muito aquém, sendo muito recentes e frágeis. Desde a guinada da humanidade para o viés que priorizou a agricultura, a posse da terra e domínio dos "mais fracos", notadamente as mulheres e a natureza, as condutas se voltaram para referenciar uma cultura competitiva,

\footnotetext{
20 Trata-se de propostas para aperfeiçoamento dos marcos constitucional, legal e infralegal da gestão de águas no Brasil. As propostas foram submetidas e discutidas com vários seguimentos da sociedade, resultando no documento final. Disponível em <www.ana.gov.br $\geq$.
} 
cartesiana, segmentária e racional, em detrimento da cooperação, da fraternidade. 0 movimento feminista, dentre outras pautas, vem retomar o papel do ser humano no planeta, de forma mais íntegra e agregadora, tendo como norte o direito de decidir sobre sua vida e seu caminho e, principalmente em mirar a irmanada em solicitações de todas as mulheres, na forma da sonoridade.

Com esse teor, a partir da terceira onda do movimento feminista, tem origem a ideia do ecofeminismo. Falando a respeito das memórias do Planeta Fêmea, Rosiska ${ }^{21}$ reforça que as mulheres foram rompendo lugares e pautas proibidas, em prol da "ordem da Vida", formulando um novo projeto civilizatório.

0 ecofeminismo, pautado na ética, no bem-querer, na dignidade de todas e exaltando a vida em todos os sentidos, coaduna-se com os contemporâneos posicionamentos voltados para proteção e defesa dos bens da natureza, e dentre eles, a água.

Percebe-se que a gestão eficiente e ética desse bem tão precioso que determina a continuidade da vida, ainda está amarrada em visões apartadas, com normas jurídicas distanciadas de uma proposta integradora de verdade. Ora, recebe guarida de normas ambientais, ora está submetida à regência de normas voltadas para seus usos no âmbito da seara de uma política hídrica. Sem contar com outras regras de setores que estão atreladas ao uso da água, como a área de energia, saneamento, alterações climáticas, saúde, dentre outros.

Este intrincando modelo de arquitetura jurídica não conta com a participação inclusiva das mulheres. E o pouco que acontece, ainda reproduz uma forma de conduta auferida pelos homens: sob a égide da ciência com uma leitura das conjunturas sociais e ecológicas, voltada para a dominação e competitividade.

O século XXI, sob os auspícios dos caminhos do século passado, já inaugura um novo porvir, da pós-verdade, da pós-ciência, da visão holística e endereçamentos muito próximos das pautas femininas, voltadas para entender e apoiar a visão de Gaia, nossa mãe Terra. Nessa perspectiva, deve-se preservar em nome das presentes e futuras gerações, não só o desenvolvimento sustentável, mas o envolvimento sustentável.

\section{Referências}

Agencia Nacional de Aguas ANA. Site institucional. Recuperado de: <http:// www.ana.gov.br>

Agencia Nacional de Vigilância Sanitária ANVISA. Site institucional. Recuperado de: <http:// portal.anvisa.gov.br>.

Biblioteca Virtual De Direitos Humanos (SP). Recuperado de: <http://www.direitoshumanos.usp.br>.

Biehl, J. (2011) A mulher e a natureza: uma mística recorrente. Le monde diplomatique, maio Recuperado de: < http://diplomatique.org.br/a-mulher-e-a-natureza-uma-mistica-recorrente/>.

Boff, L. (s.d.) Recuperado de: <http://grupelho.com/textos/principiofeminino.htm>.

Colerato, M. (s.d.) Ecofeminismo, novas perspectivas e desafios para o feminismo animalista. Recuperado de: http://www.modefica.com.br/ecofeminismo-novas-perspectivas-e-desafios/\#.WqksbOjwaUk

Cordeiro, R. et al. (2012) Mulheres e água: a experiência da rede de mulheres rurais da América Latina e do Caribe. Revista Anthropológicas, ano 16, 23(1).

ENGELS, F. (2015) Origem da família da propriedade privada do Estado. São Paulo: Edições Nosso Livro.

21 Rosiska Oliveira, Memórias do Planeta Fêmea. Estudos Feministas $n^{\underline{0}}$ 0/92. Disponível em <https:// periodicos.ufsc.br/index.php/ref/article/viewFile/15805/14298>. Cabe como explicação a respeito do Planeta Fêmea: foi palco de reunião de mulheres durante a Rio 92. 
Globo (2011) Bom dia Brasil, edição de 31 de março de 2011. Recuperado de: http://g1.globo.com/bomdia-brasil/noticia/2011/03/presenca-de-agrotoxicos-em-leite-materno-assusta-mulheres-de-mt.html

Jornal GGN. Recuperado de: <https://jornalggn.com.br/blog/luisnassif/as-religioes-monoteistas-e-otrato-dado-as-mulheres>.

MAB. Recuperado de: http://www.mabnacional.org.br/noticia/semin-rio-discute-luta-das-mulheresatingidas-por-direitos

Mulher 360+. Recuperado de: http://movimentomulher360.com.br

Mulhoz, D. (s.d.) Mulheres e Mudanças Climáticas. Recuperado de: <https://

deborahmunhoz.wordpress.com/publicacoes/artigos/mulheres-e-mudancas-climaticas/>.

Oliveira, R. (s.d.) Memórias do Planeta Fêmea. Estudos Feministas no $0 / 92$. Recuperado de: <https:// periodicos.ufsc.br/index.php/ref/article/viewFile/15805/14298>.

Radio Caracol. Recuperado de: <http://caracol.com.co/radio/2018/04/23/ecologia/ 1524520305_916811.htm>

Ramíirez, L.B.F. (2002) Los derechos de las mujeres a la tierra, agua y otros recursos naturales. Manual de capacitación para personal técnico de proyectos de desarrollo rural, instituciones públicas, y de la cooperación internacional. Coordinación General del Proyecto Sembrando Cambios en Centroamérica. Serie Metodológica Sembrando Cambios Fundación Arias para la Paz y el Progreso Humano.

Shearing, H. (s.d.) As sufragistas eram insultadas antigamente assim como muitas mulheres são hoje nas redes sociais. Recuperado de: <https://www.buzzfeed.com/hazelshearing/sufragistas-xingadas-comohoje-mulheres-sao> 